\title{
The effect of thickness measurement on numerical arterial models
}

\author{
Serena de Gelidi ${ }^{\mathrm{a}, 1}$, Gianluca Tozzi ${ }^{\mathrm{a}}$, Andrea Bucchi ${ }^{\mathrm{a}, *}$ \\ ${ }^{a}$ School of Engineering, University of Portsmouth, United Kingdom
}

Number of words: 6614

Number of words in the abstract: 212

\footnotetext{
${ }^{*}$ Corresponding author

Email address: andrea.bucchi@port.ac.uk (Andrea Bucchi )

${ }^{1}$ Present address: School of Science \& Technology, Middlesex University, United King-
} dom 


\section{Abstract}

Several optical-based techniques for measuring the sample thickness (ST) of soft tissues have been proposed in the literature to overcome the limits of hand-operated procedures. However, ST measurement still remains arbitrary. The stress calculated during an experimental procedure, usually based on a constant thickness value for all samples, cannot be considered representative of the actual stress experienced by the tissue. Therefore, a new optical methodology to measure ST is proposed and compared to four different thickness estimations. A simplified aortic geometry, under physiologic pulsatile conditions, is used to assess the impact of ST measurement on stress predictions. An additional computational model investigates the effect of such thickness values on critical pressure levels that may instigate aneurysm formation in a homogeneous or artificially modified geometry. Comparing the results obtained for the application of a pulsatile load, wall stress values associated to minimum $\mathrm{ST}$ are at least $24 \mathrm{kPa}$ inferior to maximum $\mathrm{ST}$. Critical pressure values appear to be inversely proportional to ST estimation: simulations, associated to maximum ST, predict aneurysm formation for pressure levels at least $7 \mathrm{kPa}$ inferior to minimum ST outcomes. Finally, the role of the strain-energy function used to fit the experimental data is demonstrated to be fundamental for predictions of aneurysm formation.

Keywords: Thickness, Soft tissue, Finite element, Aneurysm, Optical 


\section{Introduction}

Thickness measurement of soft tissues is notoriously difficult, as these materials deform significantly even when low loads are applied. The thickness value affects the calculation of engineering stress, as it is adopted to estimate the undeformed cross-sectional area of the sample. Hence, the stress-strain curve, describing the tissue mechanical behaviour, can be severely affected. Particular emphasis is given to numerical prediction associated to life threatening diseases, such as aneurysm rupture. However, sophisticated numerical models often rely on mechanical responses obtained from experimental tests. Therefore, experimental data used in the model need to be acquired more rigorously. Furthermore, a convenient strain-energy function (SEF) needs to be used to facilitate predictions of stress distribution across the vessel wall thickness under physiological or pathological loads. Unique mechanical behaviours emerge from each SEF applied to the same original data set (de Gelidi et al., 2016).

Throughout experimental testing, force values are objectively measured by the load cell, while the evaluation of $\mathrm{ST}^{2}$ is discretionary with no universal methodology adopted. Typically, the thickness is assumed constant for all samples tested (Choudhury et al., 2009) and rarely it is estimated for each specimen (Sokolis et al., 2002; Pierce et al., 2015). As a standard protocol is still missing, even some of the most recent studies fail to specify the methodology adopted to evaluate the specimen thickness (Vahapoglu et al., 2011; Bailly et al., 2012, 2014). Currently, a variety of experimental methods are

\footnotetext{
${ }^{2}$ Sample Thickness
} 
available to measure the thickness, including a laser micrometer (Sokolis et al., 2002; Di Martino et al., 2006; Iliopoulos et al., 2009), a video-extensometer (Holzapfel et al., 2005; Weisbecker et al., 2012), a constant force thickness indicator (Choudhury et al., 2009), digital callipers (Fitzpatrick et al., 2010; Raghavan et al., 2011; Stemper et al., 2007) or a dial gauge (Sugita and Matsumoto, 2013). Following the authors suggestions (de Gelidi et al., 2015), latest works (Deplano et al., 2016) started to estimate sample thickness by image processing. However, no agreement has been reached to date about the reference configuration that should be used to measure the ST, as they can be totally unloaded (Vande Geest et al., 2006), loaded into grips (Raghavan et al., 2011) or sandwiched between metal plates (Sugita and Matsumoto, 2013) when the measurement is conducted.

Finite element solutions are effective to predict and assess stress and strain, throughout the model, i.e. arterial wall, and provide additional insight compared with various analytical studies. Such computational models typically evaluate the effect of several boundary conditions, i.e. supra-physiologic loading (Schmidt et al., 2015), and different tissue modelling strategies, i.e. isotropic (Delfino et al., 1997; Wang et al., 2002; Giannakoulas et al., 2005; Giannoglou et al., 2006; Shang et al., 2015) or anisotropic (Holzapfel et al., 2004; Ma et al., 2007; Rodríguez et al., 2008; Badel et al., 2011; Alhayani et al., 2013). Recently, it has been demonstrated that variable wall thickness finite element models, compared to uniform designs, produce significantly different computational predictions for aneurysm expansion (Shang et al., 2015). Shang et al. (2015) demonstrated numerically that the inclusion of locally variable wall thickness allows aneurysm expansion to to be explored. 
Since such thickness values have not been validated, Shang et al. emphasized that no universal measuring technique has been established for tissue specimens. Existing literature regarding abdominal aortic aneurysms mainly focus on aneurysm growth (Volokh and Vorp, 2008; Watton et al., 2009; Shang et al., 2015) or aneurysm rupture for idealised (Rodríguez et al., 2008; Volokh and Vorp, 2008; Doyle et al., 2009) or patient specific geometries (Giannoglou et al., 2006; Gasser et al., 2010, 2014), with a clear absence of any investigation of aneurysm formation. In this context, the studies of Fu et al. (2008); Rodríguez and Merodio (2011); Alhayani et al. $(2013,2014)$ are an exception. However, the initial cylindrical configuration is usually assumed to have uniform wall thickness. To the best of the authors knowledge, no study has explored the effect of variable wall thickness on aneurysm formation based on experimental data related to soft tissues. Hence, this aspect represents the main novelty of the current investigation.

The present study aims primarily at investigating the impact of using five different possible methodologies to estimate the ST on finite element predictions for aneurysm formation. Healthy porcine descending aortas have been characterized by means of uniaxial tensile tests. Subsequently, five stressstrain responses have been obtained from the following thickness values:

- the average of all points from the selected sample (ST1)

- three points from the selected sample (ST2)

- the minimum of all samples tested (ST3)

- the maximum of all samples tested (ST4) 
- the average of all samples tested (ST5).

The resulting mechanical behaviours have then been imported in two computational models of aorta, evaluating the physiologic behaviour and the aneurysm instigation respectively.

Since it is reported that the pre-stretch is fundamental to achieve a mechanically stable deformed configuration (Rachev, 2009), such feature has been included as a boundary condition to model the physiologic cardiac activity (Lee et al., 2012; Badel et al., 2013). On the other hand, elastic instability, that could lead to aneurysm formation, was investigated by modified Riks method (Wriggers, 2010; Bucchi and Hearn, 2013a,b; Alhayani et al., 2014). The aortic wall has been modelled as isotropic, an assumption widely adopted in the literature (Raghavan and Vorp, 2000; Giannakoulas et al., 2005; Isaksen et al., 2008; Scotti et al., 2008; Gasser et al., 2010; Wang and Li, 2011). Finite element simulations allowed a precise comparison of results in order to highlight the role of ST. Predictions in terms of radial stretch, peak wall stress and critical pressure values have been compared in association to the ST estimation and the SEF used to fit the stress-strain curve.

As an additional analysis of aneurysm formation, the influence of local artificial imperfections in the FE geometry is also addressed here. Different to studies focused on pathological tissues, the investigation of such imperfection appears novel as it aims to understand whether a local different geometry may lead to aneurysm formation in a healthy aorta.

It is worth emphasizing that the present study highlights, in the context of numerical simulations, the need for awareness of experimental data input. 


\section{Materials and methods}

An overall summary of the methodology adopted in the present study is presented in Figure 1. Further details on each step are reported in the following sections.

[Figure 1 about here.]

\subsection{Sample preparation and uniaxial test}

Fresh porcine aortas were collected from a local farm house about one hour after sacrifice. The tissue was then stored in isotonic saline solution at $-20^{\circ} \mathrm{C}$ within 4 hours (Chow and Zhang, 2011). Dumb-bell shapes (35 mm long and $2 \mathrm{~mm}$ wide in the narrow part) were cut out longitudinally from thoracic and abdominal aortas by means of a custom made die (ISO 37:2005 E) (ISO 37, 2005).

Thickness and initial length were optically determined for each sample mounted between grips in the initial configuration, by means of an in house Matlab script (Mathworks, Massachusetts, US). In order to enhance the contrast of the region of interest (ROI) and to facilitate edge detection in the image segmentation, a black background was applied for the estimation of the thickness. Similarly, a white background was used to measure the initial length, as strips needed for the use of the video-extensometer were black. In both cases, the Sobel edge detection method (Parker, 2010) was applied on the ROI, which was manually selected (Fig. 2). Pixel conversion in $\mathrm{mm}$ was based on the grip dimensions, previously measured by means of a digital calliper.

[Figure 2 about here.] 
A total of 12 samples, 6 for the thoracic and 6 for the abdominal aorta, were pre-conditioned by 5 cycles performed at $1.2 \mathrm{~Hz}$. Uniaxial tensile tests were carried out at $0.2 \mathrm{~mm} / \mathrm{s}$ using a BOSE (Electroforce 3200, Bose Corporation, USA) machine equipped with a $225 \mathrm{~N}$ load cell. In order to guarantee the accuracy of strain measurement for aortic samples, a preliminary test was carried out. Hence, the displacement achieved during uniaxial tensile tests was simultaneously recorded by the cross-head of the machine and a videoextensometer. As a result, an average strain difference of $35 \%$ between the measuring techniques was appreciated. In addition, the axial strain of tissue specimen is commonly measured by means of the video-extensometer (Lally et al., 2004; García et al., 2011; Maher et al., 2012; Peña et al., 2015). Therefore, the use of the video-extensometer has been valued as the best compromise between accuracy and rapidity. Through the test, the displacement between the stickers, applied on the sample surface, was measured by a Messphysik video-extensometer with a field of view ranging from $50 \mathrm{~mm}$ to $0.4 \mathrm{~m}$ (Messphysik Materials Testing GMBH, Austria). The recording has been activated before any movement of the cross-head and stopped manually after the end of the test.

\subsection{Data analysis and fitting}

Five distinct methodologies were applied to estimate the ST. As shown in Fig. 2C (Measure of thickness), the side view of the sample was examined to calculate the ST. Although the thickness may vary along the sample width $(2 \mathrm{~mm})$, such local variations are considered negligible compared to the magnitude of ST. This is corroborated by the reduced change in thickness measured along the longitudinal direction of the sample $(12 \mathrm{~mm})$. However, 
the side projection captured the maximum local thickness for each section, which is further referred as point. The first two methods are based on just one sample, producing an average mechanical response: the sample specific thickness (ST1), retrieved using the Matlab script, and the average of specimen thickness in three points (ST2), as described in the literature (Zemanek et al., 2009; Fitzpatrick et al., 2010). ST1 takes into account all points in the ROI (Fig. 2C), while ST2 considered just the top, middle and bottom points in the ROI. The remaining three methods are based on the overall experimental series, using all the specimens to retrieve the mathematical minimum (ST3), maximum (ST4) and average (ST5) thickness for the abdominal and thoracic region of the aorta.

The aortic wall was treated as incompressible and isotropic since only uniaxial properties were measured. Subsequently, stress-strain data were described by means of different mathematical formulation, where $W$ indicates the recoverable energy stored in such material as it deforms. An integral approach for the SEF is represented by the Marlow model (Marlow, 2003), where the nominal uniaxial stress $\tau_{1}(\epsilon)$ is integrated over the strain interval $\left[0, \epsilon^{*}\right]$ :

$$
W(\epsilon)=\int_{0}^{\epsilon^{*}} \tau_{1}(\epsilon) \mathrm{d} \epsilon
$$

Another approach consists of fitting data with other SEF such as the following strain-energy functions in Abaqus (v. 6.14, Dassault Systèmes S.A., France):

Ogden $\left(1^{\text {st }}, 2^{\text {nd }}\right.$ and $3^{\text {rd }}$ order $)$ (Ogden, 1972)

$$
W=\sum_{i=1}^{N} \frac{\mu_{i}}{\alpha_{i}}\left(\lambda_{1}^{\alpha_{i}}+\lambda_{2}^{\alpha_{i}}+\lambda_{3}^{\alpha_{i}}-3\right)
$$


where $N$ indicates the order of the function, $\lambda_{i}$ represent the principal stretches, $\mu_{i}$ and $\alpha_{i}$ are temperature-dependent material parameters that allow a good fit of the theoretical description to the experimental data (Ogden, 1972). In Abaqus, the factor multiplying the sum of deviatoric principal stretches is different, being $2 \mu_{i} / \alpha_{i}^{2}$.

Yeoh (Yeoh, 1993)

$$
W=C_{10}\left(I_{1}-3\right)+C_{20}\left(I_{1}-3\right)^{2}+C_{30}\left(I_{1}-3\right)^{3}
$$

where $I_{1}$ corresponds to the first strain invariant of the right CauchyGreen deformation tensor, while $C_{10}, C_{20}$ and $C_{30}$ are fitting coefficients.

Neo-Hookean (Treloar, 1943)

$$
W=C_{10}\left(I_{1}-3\right)
$$

which can be viewed as a simplification of Yeoh's model.

\subsection{Finite element modelling}

Experimental data were imported in a simplified aortic geometry, modelled in Abaqus as a hollow cylinder with radius equal to $10 \mathrm{~mm}$ (Wang and Parker, 2004) and length $200 \mathrm{~mm}$. A mesh sensitivity was carried out and a final mesh of 3264 elements (64 elements in circumferential direction and 51 elements in longitudinal direction) was deemed as appropriate, showing independence of critical pressure respect to the number of elements. Four node shell elements with reduced integration (S4R) were adopted to mesh the geometry (Raghavan and Vorp, 2000; Giannoglou et al., 2006; Badel et al., 
2013). The thickness of the arterial wall for each model has been assumed to be the average value estimated from experimental tests: $2.5 \mathrm{~mm}$ for the thoracic and $1.64 \mathrm{~mm}$ for the abdominal aorta. Such choice allows to evaluate the sole role of experimental measurements on numerical models. Material is assumed isotropic, incompressible and described by constitutive models as detailed in Section 2.2. Previous studies assumed the stress in the load-free configuration, in which the arterial wall is not subjected to any loads, to be negligible (Raghavan and Vorp, 2000; Wang et al., 2002; Georgakarakos et al., 2010). The same assumption has been made for models presented in the following sections. Two distinct analyses have been carried out to simulate the physiologic inflation and the aneurysm formation (Figure 1). Appropriate boundary conditions and loads are detailed in the following sections for the two specific cases analysed.

\section{Physiologic inflation}

The physiologic FE model aims to explore the effect of experimental thickness measurement on radial displacement (deformation) and stress distribution in healthy conditions. Such analysis represents a typical preliminary stage to study arterial instability (Badel et al., 2013).

If a pulsatile load, in a transient dynamic analysis, is applied directly to the structure, oscillations in the structural response are observed. Therefore, in order to model a stable and realistic aortic response under physiologic conditions, two numerical approaches have been devised: the first is based on the introduction of Rayleigh damping, the second applies a pre-stretch to the blood vessel.

Firstly, Rayleigh damping has been applied to model the energy dissipation 
in a transient dynamic analysis. A brief theoretical note is included in the Appendix. This approach aims to avoid excessive circumferential and longitudinal displacement fluctuations during the cardiac cycle. The ends of the arteries are considered fully clamped (Scotti et al., 2008; Avril et al., 2010; Gasser et al., 2010). The application of the pulsatile cycle is preceded by a slow inflation of the aorta up to the diastolic pressure value $(80 \mathrm{mmHg})$, see Figure 5A (1-5 seconds). The pressure waveform adopted (Scotti et al., 2008) was normalized on 1 second of period per cycle. Despite the Rayleigh approach counting damping weighting coefficients as proportional to the mass $(\alpha)$ and stiffness $(\beta)$ matrix (Bathe, 1996), some studies preferred to take into account only the coefficient $\alpha$ (Tezduyar et al., 2008; Conway et al., 2012). However, the adopted values for arterial models are rarely published and not justified by any experimental evidence (Tezduyar et al., 2008). Therefore, in this first approach, several combinations of coefficient values have been explored (i.e. $\alpha=1 \beta=0 ; \alpha=10 \beta=0 ; \alpha=0.001 \beta=0.002 ; \alpha=0.01$ $\beta=0.01 ; \ldots)$ as discussed in more detail in Section 3.3.

The other approach is based on the physiologic evidence that arteries in situ are pre-stretched in the axial direction (Learoyd and Taylor, 1966; Horný et al., 2014). In this study a pre-stretch $\lambda=1.09$ (Learoyd and Taylor, 1966) was applied to model physiologic boundary conditions. This means that displacement boundary conditions are specified on both ends of the aorta to guarantee the axial stretch. The load is applied on the lumen of the aorta as represented in Figure 5A (0-5 seconds). In order to compare the effect of the solver on the prediction of radial displacements and wall stress, two numerical analysis have been conducted for this second approach: quasi-static 
(periodic pulsatile pressure) and transient dynamic.

\section{Aneurysm formation}

An FE model of the aorta subjected to a supra-physiologic pressure is proposed to study the instigation of the aneurysm formation. Different to the previous physiologic model, no axial pre-stretch was applied to evaluate the worst case scenario: the pre-stretch, normally ensuring arterial stability (Rachev, 2009), rapidly decreases with ageing (Horný et al., 2014). Both ends of the aortic geometry were fully constrained and an internal inflating pressure of $1 \mathrm{kPa}$ was applied as initial load for the nonlinear finite element analysis using the arc-length method (Riks, 1979; Wriggers, 2010). In a preliminary analysis, the entire length of the aorta $(20 \mathrm{~cm})$ was considered to have uniform thickness and material properties were applied using the experimental data treated according to methods ST1 - ST5 (see Introduction). This analysis permits the highlighting of the effect of sample thickness, experimentally determined, on numerical predictions.

Later, a non uniform thickness was introduced in the model. The aorta is partitioned in upper, middle and lower segment as depicted in Figure 3A. Artificial local macroscopic imperfections were introduced in the computational model to understand whether geometrical alterations are critical for aneurysm formation. Particularly, an abrupt axysimmetrical ring imperfection (Lopes et al., 2007) in the central part of the aorta was produced, reducing by $50 \%$ the thickness of the shell in the central part of the aortic model (Figure 3B). In order to figure out whether the profile of the alteration may affect the results, the ring imperfection has been subsequently smoothed assuming a sine shape (Fig. 3C). Finally, the authors decided to investigate 
the existence of a threshold, below which aneurysm may be predicted in a healthy thoracic aorta presenting local thickness reduction.

[Figure 3 about here.]

\section{Results}

The findings of the study are presented in four sections. The first one details the thickness measurements collected during the experimental campaign, needed to post-process the data sets (Figure 1). The second one reports the parameters that fit experimental data to the constitutive models. The following sections describe the outcomes produced by the numerical models, which mimic the physiologic and pathological behaviour of the aorta.

\subsection{Thickness values}

The application of the optical method estimated a sample-specific thickness (ST1) of $2.22 \mathrm{~mm}$ for the thoracic and $1.67 \mathrm{~mm}$ for the abdominal aorta. Out of six samples tested for each aortic region, the average stress-strain response has been selected. Hence, the thickness values above refer to such specimens. In addition, thickness values of thoracic samples range from a minimum (ST3) of $2.12 \mathrm{~mm}$ to a maximum (ST4) of $3.05 \mathrm{~mm}$, the average of all specimens (ST5) being $2.56 \mathrm{~mm}$. The methodology averaging only three measurements (ST2), within the ROI of the selected sample, produced a thickness value of $2.47 \mathrm{~mm}$.

Abdominal samples thickness values extend from a minimum (ST3) of 1.28 $\mathrm{mm}$ to a maximum (ST4) of $2.18 \mathrm{~mm}$, the average of all specimens (ST5) being $1.64 \mathrm{~mm}$. The average of three points (ST2) in the ROI of the selected sample has been estimated to be $1.8 \mathrm{~mm}$. 


\subsection{Fitting of experimental data}

The experimental stress strain curves for the thoracic and abdominal aorta are presented in a Figure 4 . In the plots also the results for the four fittings models (Neo-Hookean, Yeoh, $2^{\text {nd }}$ order Ogden and Marlow) are presented. The correspondent fitting parameters are reported in Table 1 . It is worth noting that the Marlow strain-energy function does not require fitting as described in Section 2.2 and hence no fitting parameters are reported in Table 1.

[Table 1 about here.]

[Figure 4 about here.]

\subsection{Physiologic model}

Several attempts were performed to carry out a transient dynamic analysis including Rayleigh damping to the aortic model, in many cases excessive circumferential fluctuations were generated. For instance, whether a high value of mass proportional damping was assigned (i.e. $\alpha=2, \beta=0$ ), instabilities arose from the end of the second cardiac cycle: the aorta appears to fluctuate around the axial axis. On the other hand, a low mass proportional damping insured a complete stability during the inflation of the aorta (i.e. $\alpha=0.01, \beta=0.02)$. However, the lack of physical relevance for the numerical value of these damping parameters in the context of soft tissue, have motivated the authors to investigate an alternative approach. The applica-

tion of the pre-stretch to the aortic model has been successful in avoiding excessive oscillations, as reported in Fig. 5B and C. 
[Figure 5 about here.]

It was noticed that the initial transient is needed to avoid oscillations that otherwise appear at the beginning of the periodic pressure wave (Fig. $5 \mathrm{~A}$ ). Responses in terms of radial displacement (Fig. 5 B) and Von Mises stress (Fig. $5 \mathrm{C}$ ) recorded for a representative node in the middle of the aortic model show the instantaneous behaviour of the aorta and the absence of instabilities. Although von Mises stress is an axis-independent scalar frequently used as an indicator of material failure in classical engineering analyses, it is also extensively used to assess the maximum stress in the biomechanical field (Humphrey and Holzapfel, 2012).

Furthermore, no significant difference has been observed in the comparison of the transient and the quasi-static analyses, due to the minimum scatter of radial displacement $\left(<10^{-9} \mathrm{~m}\right)$ and Von Mises stress $(0.516 \mathrm{kPa})$ in correspondence to inflating pressure peaks. However, some oscillations may occasionally be observed at the end of the $3^{\text {rd }}$ cycle during dynamic simulations. The effect of the ST on quasi-static predictions is captured in Tab. 2a for the thoracic part and in Tab. $2 \mathrm{~b}$ for the abdominal part of the aorta. Constitutive models providing the best fitting of uniaxial mechanical response are also reported, allowing a comparison of the maximum radial displacement and wall stress values calculated in the central part of the model.

[Table 2 about here.]

\subsection{Aneurysm formation}

In the interpretation of results, an aneurysm was considered formed under the fulfilment of the following two conditions: Riks solver predicts an 
instability and a bulge is observed in the model. Typically, the bulge is identified by the wall stress values in the central part of the aorta appearing considerably higher compared to the rest of the model. Since von Mises stress is quite often reported to produce a prediction of aneurysm growth (Shang et al., 2015), repair (Wang and Li, 2011) and rupture (Raghavan and Vorp, 2000; Wang et al., 2002; Scotti and Finol, 2007; Rodríguez et al., 2008), it has also been adopted in this work to describe the bulge initiation.

The influence of ST in the instigation of an aneurysm is explored for both the thoracic and abdominal aorta. In the case of the FE model of an homogeneous thoracic aorta, the only SEF that predicts aneurysm formation is the Neo-Hookean. Differently, the abdominal model experiences an aneurysm also when Marlow SEF is adopted to reproduce the experimental data. The associated critical pressure values are reported in Tab. 3.

[Table 3 about here.]

The application of an artificial ring imperfection on the aortic part leads to a substantial change in predictions for the thoracic model, since aneurysm formation is now predicted by Marlow SEF. The critical pressure values computed for an abrupt or smoothed ring imperfection are shown in Tab. 4a. Further simulations, using thickness reduction between $-30 \%$ and $-25 \%$, did not generate clear outcomes.

[Table 4 about here.]

In addition, the role of the percentage of reduction on the maximum Von Mises stress values seems not to be relevant(Fig. 6). 
[Figure 6 about here.]

The impact of the ST on the predicted peak wall stress in the thoracic model is shown in Fig. 7. Above a radial stretch of 0.1 the scatter between the ST is directly proportional to the scatter of the stress values.

[Figure 7 about here.]

The critical pressure values computed for the abdominal model affected by the ring imperfection (Tab. 4b) appear subjected to a reduction of about $50 \%$ compared to the corresponding homogeneous model (Tab. 3).

Furthermore, the effect of the ST on the inflating pressure in the thoracic and abdominal models can be seen in Fig. 8. Pressure values have been extracted in different stages (radial stretches), being the last one proximal to the plateau computed by Riks solver. The plateau corresponds to the value of critical pressure instigating the aneurysm formation.

[Figure 8 about here.]

\section{Discussion}

The effect of an up-to-date optical methodology to estimate the sample specific thickness is detailed. Although previous studies evaluated the wall thickness at multiple points (Raghavan et al., 2006; O'Leary et al., 2014) or by means of several techniques (Lee and Langdon, 1996), no measuring procedure has been validated among tissue samples (Shang et al., 2015). In the present work, the ST value is computed as the average of all points included 
in the ROI (Fig. 2). The impact of the present optical approach on numerical models has been compared with other methodologies, such as measuring the ST in three or four points (Sokolis et al., 2002; Pierce et al., 2015). Therefore, two main finite element models have been implemented to reproduce the physiologic cardiac activity and to study the aneurysm formation in the healthy aorta, when assumed to be isotropic. The main focus of the present work is on the role of the ST, more than on the implementation of the most reliable aortic model. Results show that even in a simplified isotropic model the scatter in prediction appears appreciable.

Five different methodologies to measure the ST have been compared. As a result, the scatter between the minimum and the maximum thickness values taken into account for each thoracic and abdominal aorta is less than $1 \mathrm{~mm}$. However, the sample-specific measures do not necessarily correspond to the average outcome of the five methodologies since they are below or equal to the median of the range.

Although a combination of Rayleigh damping coefficients $(\alpha=0.01, \beta=$ 0.02) applied to the physiologic model generated a stable outcome, it is difficult to assess whether such damping is representative of physiologic conditions. No experimental observations have been found in the soft tissue literature. Differently, a realistic pre-stretch of the aortic model produced stable outcomes, avoiding fluctuation and vibrations by means of a quasistatic approach. The quasi-static model (Pierce et al., 2015) has been preferred, as computational costs are reduced and higher stability is reached compared to the dynamic analyses. To the best of the authors knowledge, the investigation of this aspect is novel, since no previous study has compared 
such approaches to achieve stable FE outcomes. The pre-stretch approach (Alhayani et al., 2013; Badel et al., 2013; Schmidt et al., 2015) generates a minimum variation of the radial displacement in response to the systolic peak. Conversely, wall stress peaks are more pronounced and one order of magnitude higher than the pressure inflating the aorta (Fig. 5). The effect of ST on numerical predictions is clearly reflected in maximum radial stretch and wall stress values calculated for the thoracic aorta: both values increase with enlarging ST (Tab. 2a). A higher value of ST leads to a softer stress-strain behaviour of the tissue. Therefore, higher radial deformations are produced. Similar results are generated by Yeoh and Marlow constitutive models. An analogous trend is observed in the abdominal physiologic model (Tab. 2b).

The FE model for aneurysm formation in a homogeneous abdominal aorta computes critical pressure values inversely proportional to the ST (Tab. 3). As a result, the model associated to maximum ST value expects that a physiologic pressure may instigate an aneurysm formation $(\sim 122 \mathrm{mmHg})$. Such result can be explained as a limitation of the present isotropic model along with an effect of the ST over-estimation, since the minimum ST computes a pathological pressure level $(\sim 208 \mathrm{mmHg})$. Moreover, the adoption of NeoHookean SEF always predicts a bulge formation. Single elastin fibres are responsible of the arterial compliant response and they exhibit Neo-Hookean mechanical behaviour. However, the overall non-linear behaviour cannot be described by such constitutive model (Watton et al., 2009). Similarly, Kyriacou \& Humphrey (Kyriacou and Humphrey, 1996) expressed their concern about the adoption of Neo-Hookean SEF to describe soft tissue behaviour. 
This is why results of Neo-Hookean simulations are not presented as demonstration of aneurysm formation. On the other hand, Marlow SEF avoids the curve-fitting, that may introduce artefacts on the acquired aortic material response, ensuring a controllable mechanical behaviour beyond the range of data (Marlow, 2003).

For the healthy thoracic aorta aneurysm formation is expected exclusively along a local geometrical thinning or material weakening (inflammatory process), modelled in this work as an axisymmetric ring. In order to define a safe guideline, it appears that a minimum reduction of $30 \%$, compared to the thickness of the model ends, is required to observe aneurysm formation in the thoracic aorta. Thus, a dramatic reduction in wall thickness, indicated as a possible site for an aneurysm rupture (Raghavan et al., 2006), could be responsible for aneurysm formation as well. In addition, the trend observed in the physiologic model is confirmed, since a direct and consistent effect of the sample specific thickness can be appreciated in Tab. 4a and Fig. 8. Also, critical pressure values appear to decrease with increasing degree of thinning. This outcome is supported by the abdominal results that report a reduction in pressure value directly proportional to the reduction in thickness (Tab. 4b). However, while the ST is affecting the wall stress values (Fig. 7), the reduction of the thickness in the thoracic model seems irrelevant in the wall stress predictions (Fig. 6).

The predictive capability of isotropic models based on uniaxial experimental data represents the main limitation of the present study, since they can only approximate the physiologic behaviour (Holzapfel, 2006). However, an anisotropic model and the effect of fibre orientation are beyond the scope of 
this work. In addition, residual stresses, which give rise to residual strains, are not taken into account in the present investigation.

Future works will focus on a more complex geometry along with anisotropic modelling, achieved by collecting biaxial experimental data. The optical methodology, detailed and validated in the present study, will be adopted to estimate the sample specific thickness.

\section{Conclusions}

The present investigation draws attention to the need for a standard protocol in measuring ST. Despite the assumptions introduced (e.g. isotropic model, simplified geometry), numerical analyses quantified the effect of this experimental feature in either physiologic or pathophysiologic conditions. As an example, the ST clearly alters the predicted critical pressure instigating the bulging appearance. Therefore, it is recommended to take into account all the points in the ROI, as devised in the ST1 methodology. Given the biological variability of soft tissues, selecting only a number of points would lead to different numerical predictions.

The current study also highlighted a limited awareness in the literature of Rayleigh damping applied to soft tissues. Further investigations are needed to fully assess the physical relevance for the values of the Rayleigh damping parameters used to stabilise the structural response.

As an additional outcome of this study, a local thickness reduction in the FE model, over a certain threshold, could be one of the triggers for the aneurysm formation in a healthy aorta. Further efforts are required to verify such hy-

pothesis, overcoming some of the current FEM assumptions. Lastly, such 
prediction appears also strictly dependent on the constitutive model adopted to fit the aortic mechanical response. Therefore, it is worth comparing multiple SEFs to assess the reliability of prediction models, since pathological behaviour may arise just from a particular function.

\section{Appendix}

The equation of motion of a linear dynamic system can be written as

$$
M \ddot{x}+C \dot{x}+K x=f
$$

where $M, C$ and $K$ are the mass, damping and stiffness matrices and $x$ and $f$ are displacement and force vectors, respectively. Hence, $\ddot{x}$ indicates the acceleration, while $\dot{x}$ is the velocity. A common approach to introduce damping in a structural analysis is represented by the Rayleigh decomposition:

$$
C=\alpha M+\beta K
$$

where $\alpha$ and $\beta$ are arbitrary constant coefficients (Liu and Gorman, 1995). In FEM, damping is a material property specified as part of the material definition. The $\alpha$ factor simulates a structure moving through a viscous ether, hence it gives a damping contribution proportional to the mass matrix for an element. The $\beta$ factor introduces damping proportional to the strain rate, which can be thought as damping associated with the material itself.

\section{Conflict of interest}

None. 


\section{Acknowledgments}

The authors gratefully acknowledge Prof Stephen Dilworth for his proofreading. The authors also thank Mr Colin Lupton, for his support during the experimental tests. This work was partially funded by an EPSRC grant (EP/M014711/1).

\section{References}

Alhayani, A. A., Giraldo, J. A., Rodríguez, J. F., Merodio, J., 2013. Computational modelling of bulging of inflated cylindrical shells applicable to aneurysm formation and propagation in arterial wall tissue. Finite Elements in Analysis and Design 73, 20-29.

Alhayani, A. A., Rodríguez, J. F., Merodio, J., 2014. Competition between radial expansion and axial propagation in bulging of inflated cylinders with application to aneurysms propagation in arterial wall tissue. International Journal of Engineering Science 85, 74-89.

Avril, S., Badel, P., Duprey, A., nov 2010. Anisotropic and hyperelastic identification of in vitro human arteries from full-field optical measurements. Journal of biomechanics 43 (15), 2978-85.

Badel, P., Avril, S., Lessner, S., Sutton, M., 2011. Mechanical identification of hyperelastic anisotropic properties of mouse carotid arteries. Mechanics of Biological Systems and Materials 2 (c), 11-17.

Badel, P., Rohan, C. P. Y., Avril, S., 2013. Finite Element simulation of buckling-induced vein tortuosity and influence of the wall constitutive 
properties. Journal of the Mechanical Behavior of Biomedical Materials 26, 119-126.

Bailly, L., Deplano, V., Lemercier, a., Boiron, O., Meyer, C., 2014. New experimental protocols for tensile testing of abdominal aortic analogues. Medical Engineering and Physics 36 (6), 800-804.

Bailly, L., Geindreau, C., Orgéas, L., Deplano, V., 2012. Towards a biomimetism of abdominal healthy and aneurysmal arterial tissues. Journal of the mechanical behavior of biomedical materials 10, 151-65.

Bathe, K.-J., 1996. Finite Element Procedures. Prentice Hall, New Jersey.

Bucchi, A., Hearn, G. E., 2013a. Predictions of aneurysm formation in distensible tubes: Part A Theoretical background to alternative approaches. International Journal of Mechanical Sciences 71, 1-20.

Bucchi, A., Hearn, G. E., 2013b. Predictions of aneurysm formation in distensible tubes: Part B Application and comparison of alternative approaches. International Journal of Mechanical Sciences 70, 155-170.

Choudhury, N., Bouchot, O., Rouleau, L., Tremblay, D., Cartier, R., Butany, J., Mongrain, R., Leask, R. L., 2009. Local mechanical and structural properties of healthy and diseased human ascending aorta tissue. Cardiovascular pathology : the official journal of the Society for Cardiovascular Pathology 18 (2), 83-91.

Chow, M.-J., Zhang, Y., 2011. Changes in the mechanical and biochemical properties of aortic tissue due to cold storage. The Journal of surgical research 171 (2), 434-42. 
Conway, C., Sharif, F., McGarry, J. P., McHugh, P. E., 2012. A Computational Test-Bed to Assess Coronary Stent Implantation Mechanics Using a Population-Specific Approach. Cardiovascular Engineering and Technology 3 (4), 374-387.

de Gelidi, S., Tozzi, G., Bucchi, A., 2015. Aneurysm formation: the role of sample thickness in the experimental data collection. In: 21st Congress of the European Society of Biomechanics (abstract 026). Prague.

de Gelidi, S., Tozzi, G., Bucchi, A., 2016. The Role of Pre-Conditioning Frequency in the Experimental Characterization of Hyper-Elastic Materials as Models for Soft Tissue Applications. International Journal of Applied Mechanics 08 (05), 1650066 1- 20.

Delfino, a., Stergiopulos, N., Moore, J. E., Meister, J. J., 1997. Residual strain effects on the stress field in a thick wall finite element model of the human carotid bifurcation. Journal of biomechanics 30 (8), 777-786.

Deplano, V., Boufi, M., Boiron, O., Guivier-Curien, C., Alimi, Y., Bertrand, E., 2016. Biaxial tensile tests of the porcine ascending aorta. Journal of Biomechanics 49, 2031-2037.

Di Martino, E. S., Bohra, A., Vande Geest, J. P., Gupta, N., Makaroun, M. S., Vorp, D. A., 2006. Biomechanical properties of ruptured versus electively repaired abdominal aortic aneurysm wall tissue. Journal of vascular surgery 43 (3), 570-6.

Doyle, B. J., Corbett, T. J., Callanan, A., Walsh, M. T., Vorp, D. A., McGloughlin, T. M., jun 2009. An experimental and numerical comparison 
of the rupture locations of an abdominal aortic aneurysm. Journal of endovascular therapy: an official journal of the International Society of Endovascular Specialists 16 (3), 322-35.

Fitzpatrick, J. C., Clark, P. M., Capaldi, F. M., 2010. Effect of decellularization protocol on the mechanical behavior of porcine descending aorta. International journal of biomaterials 2010, 1-11.

Fu, Y. B., Pearce, S. P., Liu, K. K., 2008. Post-bifurcation analysis of a thin-walled hyperelastic tube under inflation. International Journal of NonLinear Mechanics 43 (8), 697-706.

García, A., Peña, E., Laborda, A., Lostalé, F., De Gregorio, M. a., Doblaré, M., Martínez, M. a., jul 2011. Experimental study and constitutive modelling of the passive mechanical properties of the porcine carotid artery and its relation to histological analysis: Implications in animal cardiovascular device trials. Medical engineering \& physics 33 (6), 665-76.

Gasser, C. T., Auer, M., Labruto, F., Swedenborg, J., Roy, J., 2010. Biomechanical rupture risk assessment of abdominal aortic aneurysms: model complexity versus predictability of finite element simulations. European journal of vascular and endovascular surgery: the official journal of the European Society for Vascular Surgery 40 (2), 176-85.

Gasser, C. T., Nchimi, A., Swedenborg, J., Roy, J., Sakalihasan, N., Böckler, D., Hyhlik-Dürr, A., 2014. A Novel Strategy to Translate the Biomechanical Rupture Risk of Abdominal Aortic Aneurysms to their Equivalent 
Diameter Risk: Method and Retrospective Validation. European Journal of Vascular and Endovascular Surgery 47 (3), 288-295.

Georgakarakos, E., Ioannou, C. V., Kamarianakis, Y., Papaharilaou, Y., Kostas, T., Manousaki, E., Katsamouris, A. N., 2010. The Role of Geometric Parameters in the Prediction of Abdominal Aortic Aneurysm Wall Stress. European Journal of Vascular and Endovascular Surgery 39 (1), $42-48$.

Giannakoulas, G., Giannoglou, G., Soulis, J., Farmakis, T., Papadopoulou, S., Parcharidis, G., Louridas, G., 2005. A computational model to predict aortic wall stresses in patients with systolic arterial hypertension. Medical Hypotheses 65 (6), 1191-1195.

Giannoglou, G., Giannakoulas, G., Soulis, J., Chatzizisis, Y., Perdikides, T., Melas, N., Parcharidis, G., Louridas, G., 2006. Predicting the Risk of Rupture of Abdominal Aortic Aneurysms by Utilizing Various Geometrical Parameters: Revisiting the Diameter Criterion. Angiology 57 (4), 487-494.

Holzapfel, G. A., 2006. Determination of material models for arterial walls from uniaxial extension tests and histological structure. Journal of theoretical biology 238 (2), 290-302.

Holzapfel, G. A., Gasser, C. T., Ogden, R. W., 2004. Comparison of a multilayer structural model for arterial walls with a fung-type model, and issues of material stability. Journal of biomechanical engineering 126 (April 2004), 264-275. 
Holzapfel, G. A., Sommer, G., Gasser, C. T., Regitnig, P., Gerhard, A., 2005. Determination of layer-specific mechanical properties of human coronary arteries with nonatherosclerotic intimal thickening and related constitutive modeling. American journal of physiology. Heart and circulatory physiology 289 (5), H2048-2058.

Horný, L., Netusil, M., Vonavkova, T., 2014. Axial prestretch and circumferential distensibility in biomechanics of abdominal aorta. Biomechanics and Modeling in Mechanobiology 13 (4), 783-799.

Humphrey, J. D., Holzapfel, G. A., 2012. Mechanics, Mechanobiology, and Modeling of Human Abdominal Aorta and Aneurysms. Journal of biomechanics 45 (5), 805-14.

Iliopoulos, D. C., Deveja, R. P., Kritharis, E. P., Perrea, D., Sionis, G. D., Toutouzas, K., Stefanadis, C., Sokolis, D. P., 2009. Regional and directional variations in the mechanical properties of ascending thoracic aortic aneurysms. Medical engineering \& physics 31 (1), 1-9.

Isaksen, J. G., Bazilevs, Y., Kvamsdal, T., Zhang, Y., Kaspersen, J. H., Waterloo, K., Romner, B., Ingebrigtsen, T., 2008. Determination of wall tension in cerebral artery aneurysms by numerical simulation. Stroke 39, $3172-3178$.

ISO 37, 2005. Rubber, vulcanized or thermoplastic. Determination of tensile stress-strain properties.

Kyriacou, S., Humphrey, J. D., 1996. Influence of size, shape and properties 
on the mechanics of axisymmetric saccular aneurysms. Journal of Biomechanics 29 (8), 1015-1022.

Lally, C., Reid, a. J., Prendergast, P. J., oct 2004. Elastic behavior of porcine coronary artery tissue under uniaxial and equibiaxial tension. Annals of biomedical engineering 32 (10), 1355-1364.

Learoyd, B. M., Taylor, M. G., 1966. Alterations with Age in the Viscoelastic Properties of Human Arterial Walls. Circulation Research 18 (3), 278-292.

Lee, A. Y., Han, B., Lamm, S. D., Fierro, C. a., Han, H.-C., 2012. Effects of elastin degradation and surrounding matrix support on artery stability. AJP: Heart and Circulatory Physiology 302 (4), H873-H884.

Lee, J., Langdon, S. E., 1996. Thickness measurement of soft tissue biomaterials: A comparison of five methods. Journal of Biomechanics 29 (6), 829-832.

Liu, M., Gorman, D., 1995. Formulation of Rayleigh damping and its extensions. Computers \& Structures 57 (2), 277-285.

Lopes, S., Gonçalves, P., Pamplona, D., 2007. Influence of initial geometric imperfections on the stability of thick cylindrical shells under internal pressure. Communications in numerical methods in engineering 23, 577-597.

Ma, B., Lu, J., Harbaugh, R. E., Raghavan, M. L., 2007. Nonlinear anisotropic stress analysis of anatomically realistic cerebral aneurysms. Journal of biomechanical engineering 129 (February 2007), 88-96. 
Maher, E., Early, M., Creane, A., Lally, C., Kelly, D. J., may 2012. Site specific inelasticity of arterial tissue. Journal of biomechanics 45 (8), 13939 .

Marlow, R. S., 2003. A general first-invariant hyperelastic constitutive model. In: Busfield, J. J. C., Muhr, A. H. (Eds.), Constitutive models for rubber III. Taylor \& Francis, Lisse, pp. 157-160.

Ogden, R. W., 1972. Large deformation isotropic elasticity - on the correlation of theory and experiment for incompressible rubberlike solids. Royal society 326 (1567), 565-584.

O’Leary, S. a., Doyle, B. J., McGloughlin, T. M., 2014. The impact of long term freezing on the mechanical properties of porcine aortic tissue. Journal of the Mechanical Behavior of Biomedical Materials 37, 165-173.

Parker, J. R., 2010. Algorithms for Image Processing and Computer Vision. Vol. 29. John Wiley \& Sons, Indianapolis.

Peña, J. A., Martínez, M. A., Peña, E., 2015. Layer-specific residual deformations and uniaxial and biaxial mechanical properties of thoracic porcine aorta. Journal of the Mechanical Behavior of Biomedical Materials 50, 5569.

Pierce, D. M., Maier, F., Weisbecker, H., Viertler, C., Verbrugghe, P., Famaey, N., Fourneau, I., Herijgers, P., Holzapfel, G. A., 2015. Human thoracic and abdominal aortic aneurysmal tissues: Damage experiments, statistical analysis and constitutive modeling. Journal of the Mechanical Behavior of Biomedical Materials 41, 92-107. 
Rachev, A., 2009. A theoretical study of mechanical stability of arteries. Journal of biomechanical engineering 131 (5), 051006 1-10.

Raghavan, M. L., Hanaoka, M. M., Kratzberg, J. A., de Lourdes Higuchi, M., da Silva, E. S., 2011. Biomechanical failure properties and microstructural content of ruptured and unruptured abdominal aortic aneurysms. Journal of biomechanics 44 (13), 2501-2507.

Raghavan, M. L., Kratzberg, J., Castro de Tolosa, E. M., Hanaoka, M. M., Walker, P., da Silva, E. S., 2006. Regional distribution of wall thickness and failure properties of human abdominal aortic aneurysm. Journal of biomechanics 39 (16), 3010-3016.

Raghavan, M. L., Vorp, D. A., 2000. Toward a biomechanical tool to evaluate rupture potential of abdominal aortic aneurysm : identification of a finite strain constitutive model and evaluation of its applicability. Journal of Biomechanics 33, 475-482.

Riks, E., 1979. An incremental approach to the solution of snapping and buckling problems. International Journal of Solids and Structures 15 (7), $529-551$.

Rodríguez, J. F., Merodio, J., apr 2011. A new derivation of the bifurcation conditions of inflated cylindrical membranes of elastic material under axial loading. Application to aneurysm formation. Mechanics Research Communications 38 (3), 203-210.

Rodríguez, J. F., Ruiz, C., Doblaré, M., Holzapfel, G. A., 2008. Mechanical stresses in abdominal aortic aneurysms: influence of diameter, asymmetry, 
and material anisotropy. Journal of biomechanical engineering 130 (2), $0210231-10$.

Schmidt, T., Pandya, D., Balzani, D., 2015. Influence of isotropic and anisotropic material models on the mechanical response in arterial walls as a result of supra-physiological loadings. Mechanics Research Communications $64,29-37$.

Scotti, C. M., Finol, E. a., 2007. Compliant biomechanics of abdominal aortic aneurysms: A fluid-structure interaction study. Computers and Structures 85 (11-14), 1097-1113.

Scotti, C. M., Jimenez, J., Muluk, S. C., Finol, E. A., 2008. Wall stress and flow dynamics in abdominal aortic aneurysms: finite element analysis vs. fluid-structure interaction. Computer methods in biomechanics and biomedical engineering 11 (3), 301-322.

Shang, E. K., Nathan, D. P., Woo, E. Y., Fairman, R. M., Wang, G. J., Gorman, R. C., Gorman, J. H., Jackson, B. M., 2015. Local wall thickness in finite element models improves prediction of abdominal aortic aneurysm growth. Journal of Vascular Surgery 61 (1), 217-223.

Sokolis, D. P., Boudoulas, H., Karayannacos, P. E., 2002. Assessment of the aortic stress-strain relation in uniaxial tension. Journal of biomechanics 35 (9), 1213-1223.

Stemper, B. D., Yoganandan, N., Stineman, M. R., Gennarelli, T. A., Baisden, J. L., Pintar, F. a., 2007. Mechanics of fresh, refrigerated, and frozen arterial tissue. The Journal of surgical research 139 (2), 236-42. 
Sugita, S., Matsumoto, T., 2013. Novel biaxial tensile test for studying aortic failure phenomena at a microscopic level. Biomedical engineering online $12(1), 1-13$.

Tezduyar, T. E., Sathe, S., Schwaab, M., Conklin, B. S., 2008. Arterial fluid mechanics modeling with the stabilized space time fluid structure interaction technique. International Journal for Numerical Methods in Fluids (54), $901-922$.

Treloar, L. R. G., 1943. Stress strain data for vulcanised rubber under various types of deformation. Transactions of the Faraday Society 40, 59-70.

Vahapoglu, V., Karadeniz, S., Yazici, I., 2011. Uniaxial Tensile Testing of Rubber-Like Materials. Experimental Techniques 35 (1), 17-23.

Vande Geest, J. P., Sacks, M. S., Vorp, D. A., 2006. The effects of aneurysm on the biaxial mechanical behavior of human abdominal aorta. Journal of biomechanics 39 (7), 1324-1334.

Volokh, K. Y., Vorp, D. A., 2008. A model of growth and rupture of abdominal aortic aneurysm. Journal of Biomechanics 41, 1015-1021.

Wang, D. H. J., Makaroun, M. S., Webster, M. W., Vorp, D. A., 2002. Effect of intraluminal thrombus on wall stress in patient-specific models of abdominal aortic aneurysm. Journal of vascular surgery 36 (3), 598-604.

Wang, J. J., Parker, K. H., 2004. Wave propagation in a model of the arterial circulation. Journal of biomechanics 37 (4), 457-70. 
Wang, X., Li, X., 2011. Fluid-structure interaction based study on the physiological factors affecting the behaviors of stented and non-stented thoracic aortic aneurysms. Journal of Biomechanics 44 (12), 2177-2184.

Watton, P. N., Ventikos, Y., Holzapfel, G. A., 2009. Modelling the mechanical response of elastin for arterial tissue. Journal of Biomechanics 42 (9), 13201325.

Weisbecker, H., Pierce, D. M., Regitnig, P., Holzapfel, G. A., 2012. Layerspecific damage experiments and modeling of human thoracic and abdominal aortas with non-atherosclerotic intimal thickening. Journal of the Mechanical Behavior of Biomedical Materials 12, 93-106.

Wriggers, P., 2010. Nonlinear Finite Element Methods. Springer-Verlag, Berlin.

Yeoh, O. H., 1993. Some forms of the strain energy function for rubber. Rubber Chemistry and Technology 66, 754-771.

Zemanek, M., Bursa, J., Detàk, M., 2009. Biaxial tension tests with soft tissues of arterial wall. Engineering mechanics 16 (1), 3-11. 


\section{List of Figures}

1 Summary of the steps taken to evaluate the role of sample thickness on numerical outcomes. . . . . . . . . . . . . . 38

2 Steps of Matlab script used to measure the average thickness (bottom row) and the initial length (top row) of each sample: A) undeformed sample mounted between the grips, B) region of interest (ROI) selection and C) application of Sobel edge detection method on ROI . . . . . . . . . . . . . . . . 39

3 Schematic of artificial local imperfections introduced in the FE model of aorta. Both alterations affect the middle part (A) of the geometry. In order to study possible effects on aneurysm formation, an abrupt (B) or smoothed (C) imperfection reduces locally the thickness of the model . . . . . . . . . . . 40

4 Stress-strain plots of average thoracic (A) and abdominal (B) responses for samples featuring a sample specific thickness. Experimental data (red dots) are integrated by Marlow model (blue) and fitted by different strain energy functions: Ogden (green), Neo-Hookean (orange) and Yeoh (black). . . . . . . . 41

5 Pressure waveform inflating the FE model of aorta consisting in a ramp and three cycles (A). A pre-stretch is applied during the first second. Radial displacement of a node placed in the mid of the FE model is plotted (B), as well as resulting von Mises stress of the same node $(\mathrm{C}) \ldots \ldots$. . . . . . . . . . . 42

6 Von Mises stress [Pa] achieved in the central part of the thoracic model vs Radial stretch. Three different percentages of ring imperfection that were artificially introduced in the central part of the model are compared. The global deformation predicted for the radial stretch value is indicated by the red line 43

7 Von Mises stress [Pa] achieved in the central part of the thoracic model vs Radial stretch for different sample thickness values. The global deformation predicted for the radial stretch (red line) in relation to the specific calculated values of thickness is reported . . . . . . . . . . . . . . . . . 44 44 
8 Thickness influence on the pressure inflating the thoracic (A) and abdominal (B) aortic models. Three values of radial stretch have been selected for each model. Each bar colour is specific for a sample thickness value: the minimum of all samples (green), the average of all samples (black), the maximum of all samples (yellow), the sample specific (red) and and the average of three points (blue) . . . . . . . . . . . . . 45 


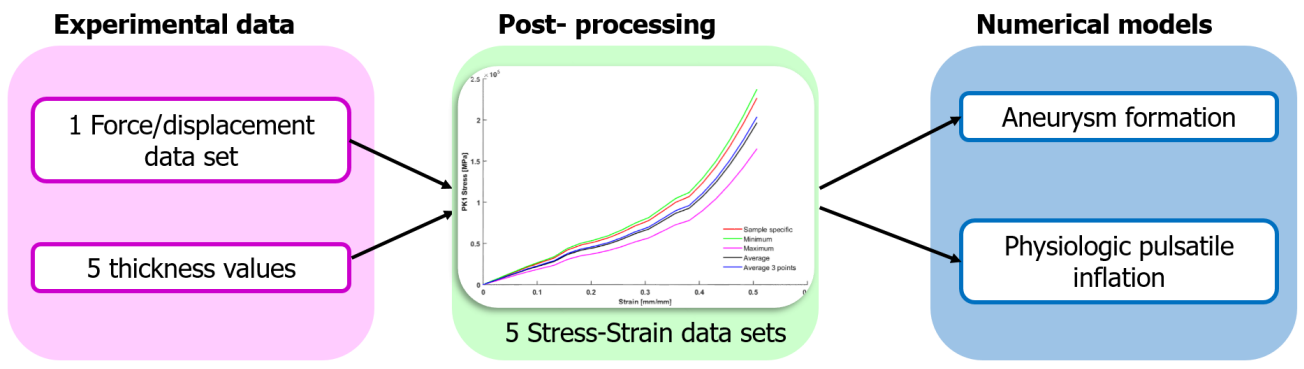

Figure 1 Summary of the steps taken to evaluate the role of sample thickness on numerical outcomes. 

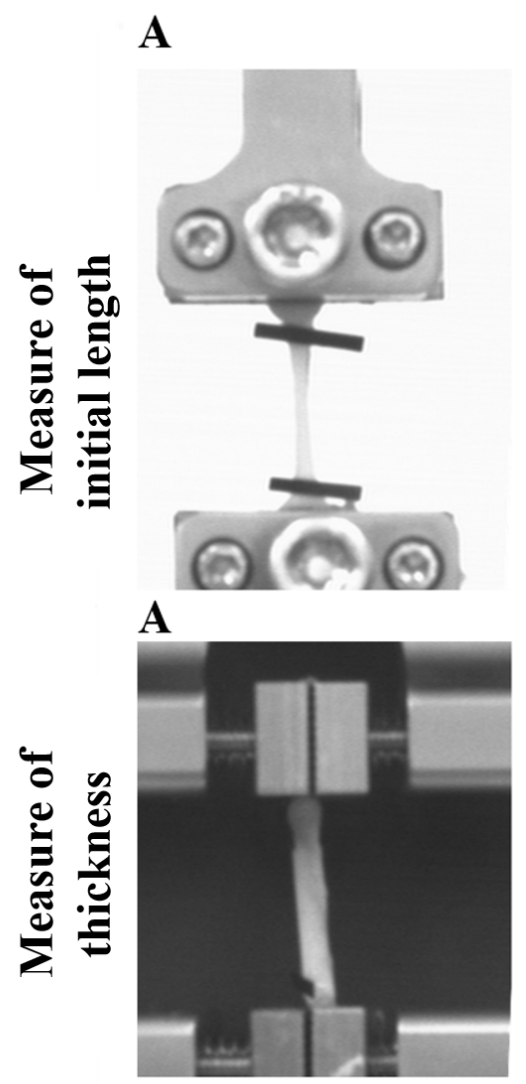

B

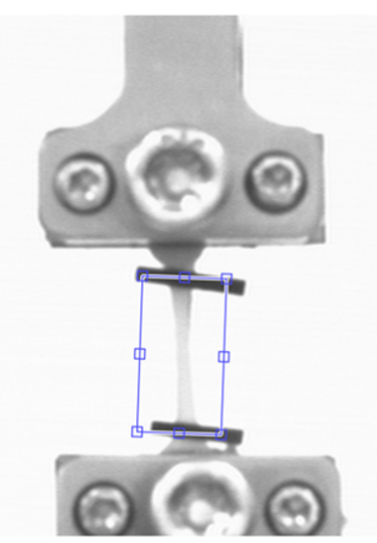

B

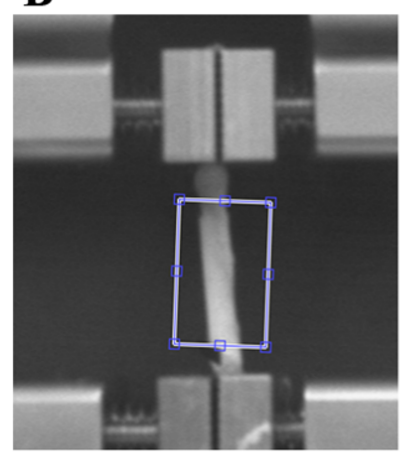

C

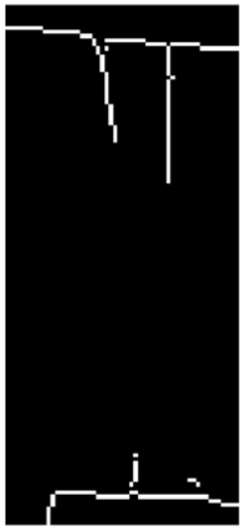

C

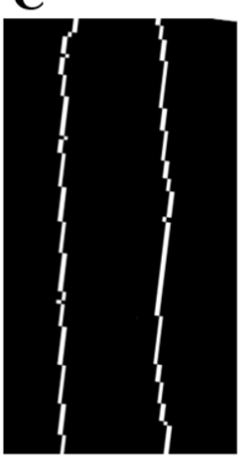

Figure 2 Steps of Matlab script used to measure the average thickness (bottom row) and the initial length (top row) of each sample: A) undeformed sample mounted between the grips, B) region of interest (ROI) selection and C) application of Sobel edge detection method on ROI 


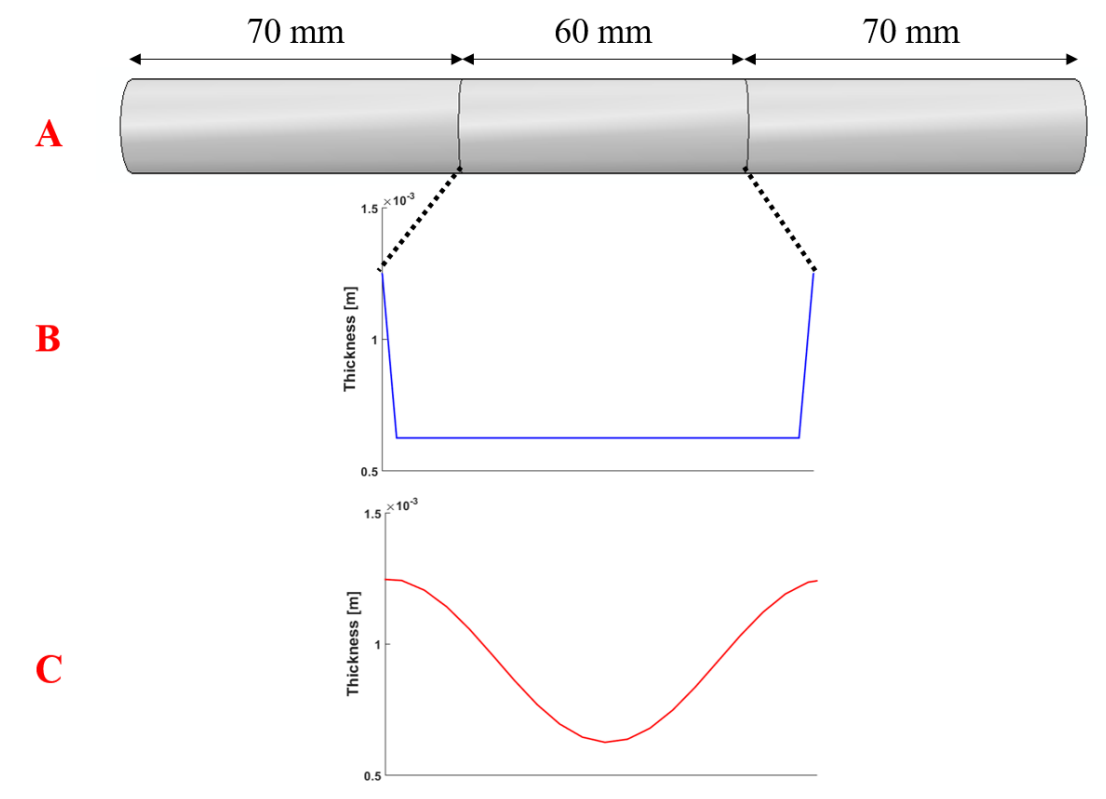

Figure 3 Schematic of artificial local imperfections introduced in the FE model of aorta. Both alterations affect the middle part (A) of the geometry. In order to study possible effects on aneurysm formation, an abrupt (B) or smoothed (C) imperfection reduces locally the thickness of the model 

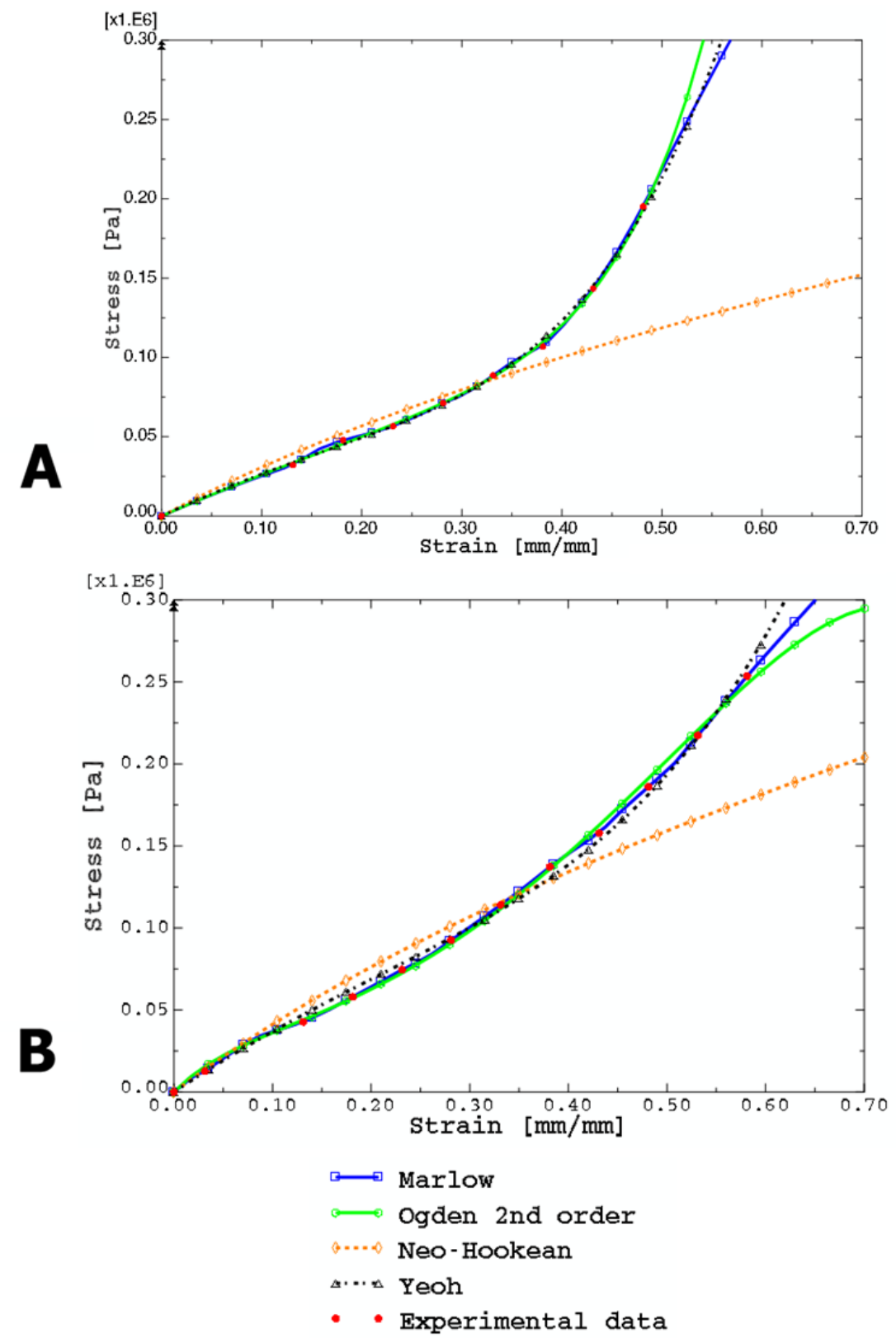

Figure 4 Stress-strain plots of average thoracic (A) and abdominal (B) responses for samples featuring a sample specific thickness. Experimental data (red dots) are integrated by Marlow model (blue) and fitted by different strain energy functions: Ogden (green), Neo-Hookean (orange) and Yeoh (black). 

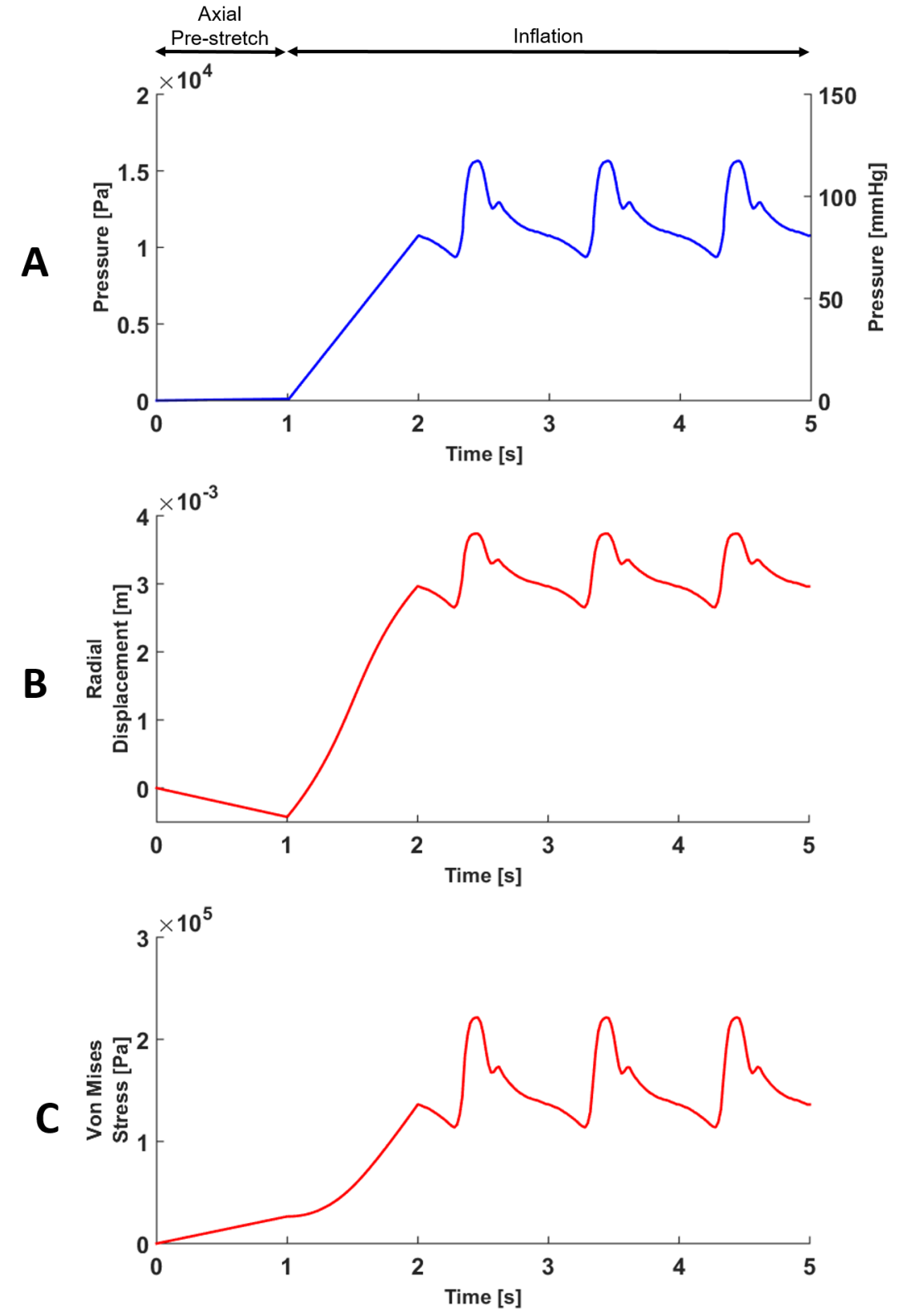

Figure 5 Pressure waveform inflating the FE model of aorta consisting in a ramp and three cycles (A). A pre-stretch is applied during the first second. Radial displacement of a node placed in the mid of the FE model is plotted (B), as well as resulting von Mises stress of the same node $(\mathrm{C})$ 


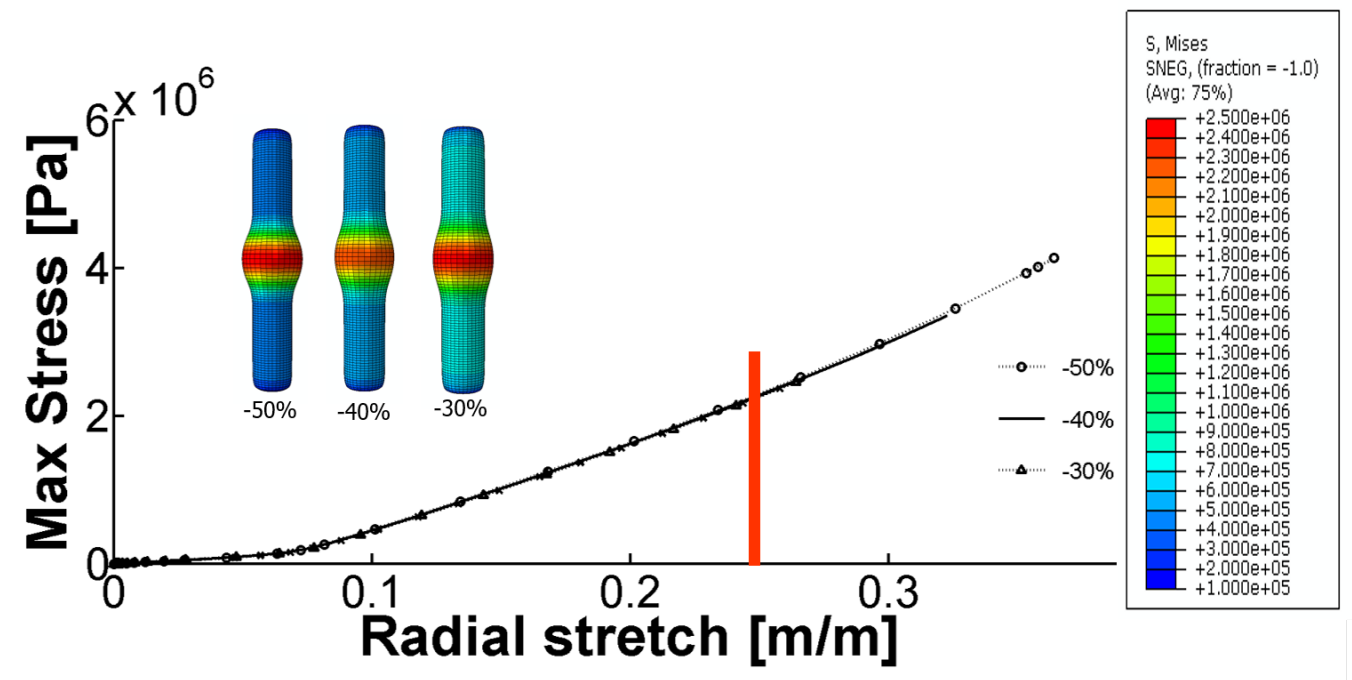

Figure 6 Von Mises stress [Pa] achieved in the central part of the thoracic model vs Radial stretch. Three different percentages of ring imperfection that were artificially introduced in the central part of the model are compared. The global deformation predicted for the radial stretch value is indicated by the red line 


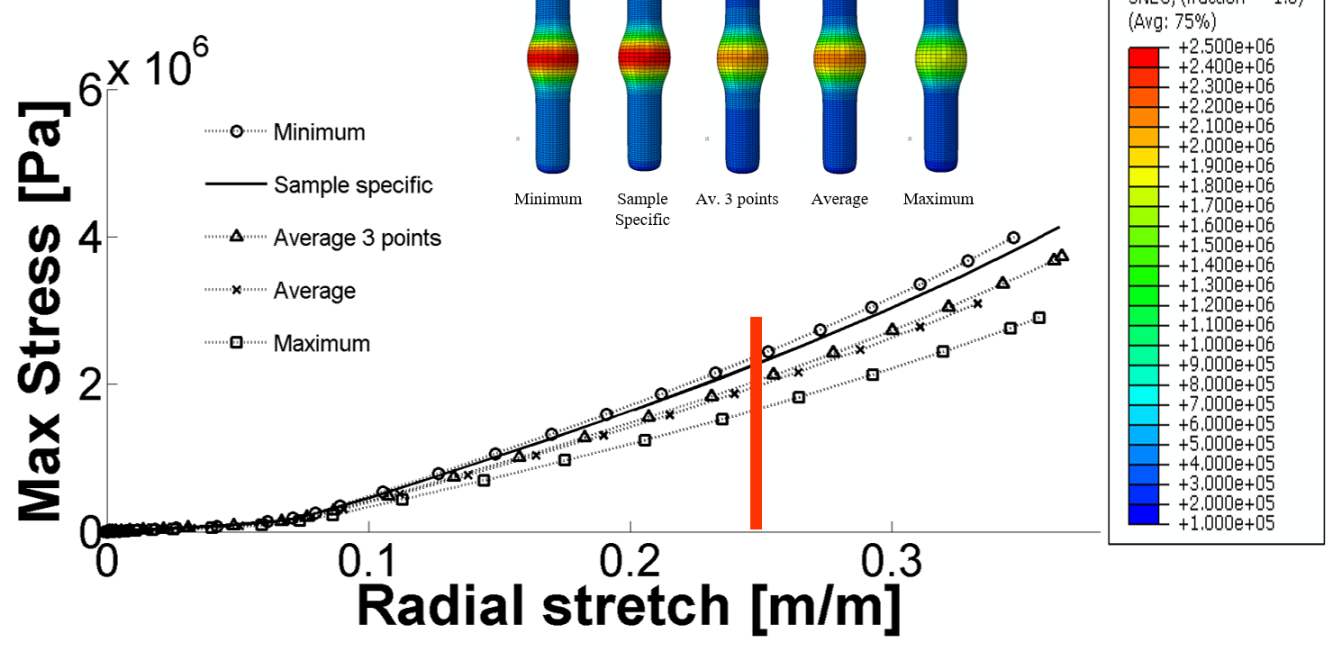

Figure 7 Von Mises stress $[\mathrm{Pa}]$ achieved in the central part of the thoracic model vs Radial stretch for different sample thickness values. The global deformation predicted for the radial stretch (red line) in relation to the specific calculated values of thickness is reported 

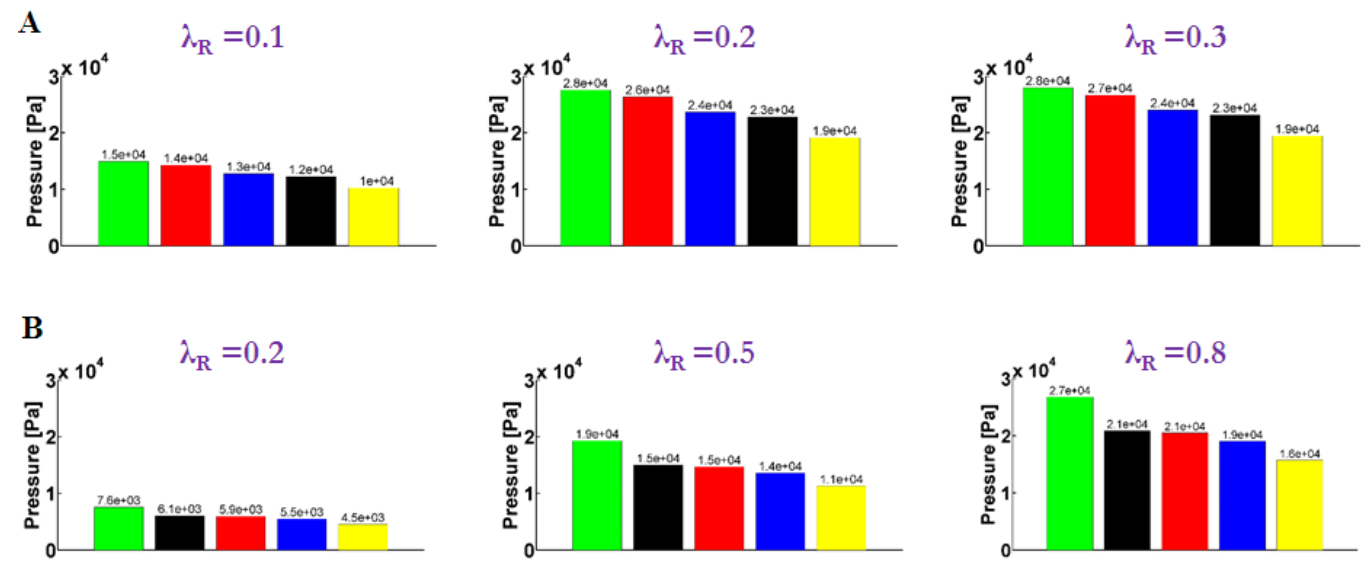

Figure 8 Thickness influence on the pressure inflating the thoracic (A) and abdominal (B) aortic models. Three values of radial stretch have been selected for each model. Each bar colour is specific for a sample thickness value: the minimum of all samples (green), the average of all samples (black), the maximum of all samples (yellow), the sample specific (red) and and the average of three points (blue) 


\section{List of Tables}

1 Fitting parameters estimated by Abaqus for average stressstrain responses obtained from uniaxial tensile tests, featuring a sample specific thickness. . . . . . . . . . . . . . . . . . . 47

2 The effect of sample thickness on the maximum radial displacement $\left(R_{d}\right)$ and maximum von Mises stress $(\sigma)$ predicted by the FE model of thoracic (a) and abdominal (b) aorta, subjected to a physiologic cardiac activity. The listed strainenergy functions assured the best fitting of the experimental data and a stable numerical outcome. Unstable numerical outcome is indicated by "/", meaning that non physical oscillations were observed. . . . . . . . . . . . . . . . 48

3 Critical pressure values $[\mathrm{kPa}]$ predicted to form aneurysm in a homogeneous FE geometry of abdominal aorta, which behaviour is evaluated for five different sample thickness values. No aneurysm indicates that no aneurysm is predicted . . . . . 49

4 Critical pressure values $[\mathrm{kPa}]$ predicted to form aneurysm in a not homogeneous model of thoracic (a) and abdominal (b) aorta, evaluated for five different sample thickness values. A geometrical ring imperfection is introduced to reduce the thickness in the middle of the FE model. No aneurysm indicates that no aneurysm is predicted . . . . . . . . . . . 50 


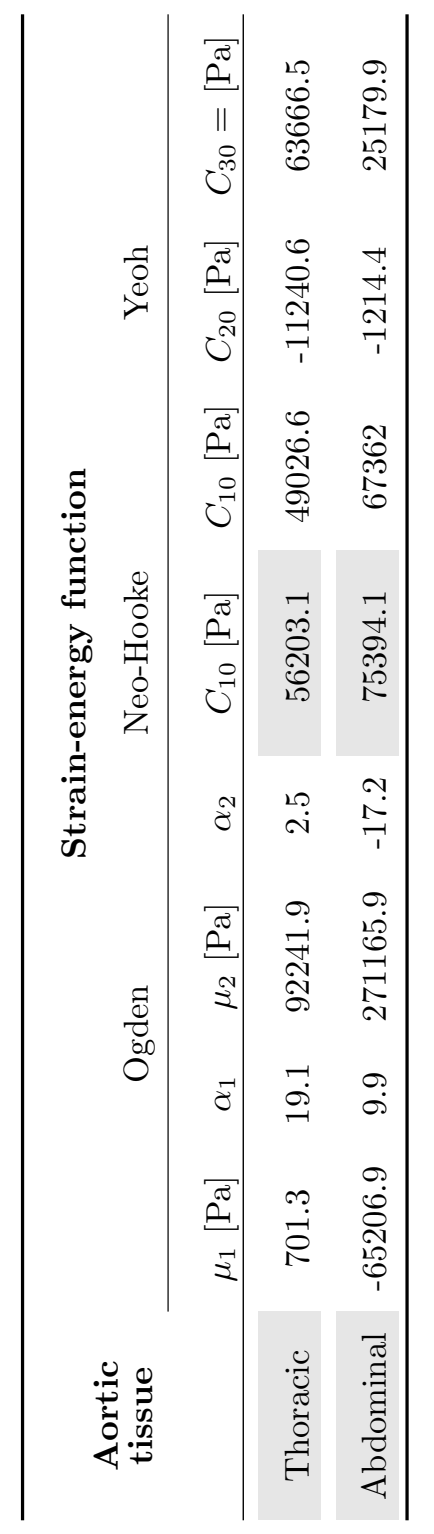

Table 1 Fitting parameters estimated by Abaqus for average stress-strain responses obtained from uniaxial tensile tests, featuring a sample specific thickness. 
(a)

\begin{tabular}{|c|c|c|c|c|c|c|c|c|c|c|}
\hline \multirow{2}{*}{$\begin{array}{l}\text { Strain } \\
\text { energy } \\
\text { function }\end{array}$} & \multicolumn{2}{|c|}{$\begin{array}{c}\text { Minimum } \\
\text { of all } \\
\text { samples } \\
(0.00212 \mathrm{~m})\end{array}$} & \multicolumn{2}{|c|}{$\begin{array}{c}\text { Sample } \\
\text { specific } \\
(0.00222 \mathrm{~m})\end{array}$} & \multicolumn{2}{|c|}{$\begin{array}{c}\text { Average } \\
\text { of three } \\
\text { points } \\
(0.00247 \mathrm{~m})\end{array}$} & \multicolumn{2}{|c|}{$\begin{array}{c}\text { Average } \\
\text { of all } \\
\text { points } \\
(0.00256 \mathrm{~m})\end{array}$} & \multicolumn{2}{|c|}{$\begin{array}{c}\text { Maximum } \\
\text { of all } \\
\text { points } \\
(0.00305 \mathrm{~m})\end{array}$} \\
\hline & $R_{d}[\mathrm{~m}]$ & $\sigma[\mathrm{kPa}]$ & $R_{d}[\mathrm{~m}]$ & $\sigma[\mathrm{kPa}]$ & $R_{d}[\mathrm{~m}]$ & $\sigma[\mathrm{kPa}]$ & $R_{d}[\mathrm{~m}]$ & $\sigma[\mathrm{kPa}]$ & $R_{d}[\mathrm{~m}]$ & $\sigma[\mathrm{kPa}]$ \\
\hline Ogden & & & & & & & & & & \\
\hline $2^{\text {nd }}$ order & 0.00469 & 269 & 0.00478 & 274 & 0.00498 & 285 & 0.00505 & 289 & 0.00538 & 317 \\
\hline Yeoh & 0.00365 & 219 & 0.00374 & 222 & 0.00395 & 228 & 0.00402 & 231 & 0.00435 & 242 \\
\hline Marlow & 0.00363 & 218 & 0.00371 & 221 & 0.00391 & 227 & 0.00397 & 229 & 0.00435 & 242 \\
\hline
\end{tabular}

(b)

\begin{tabular}{|c|c|c|c|c|c|c|c|c|c|c|}
\hline \multirow{2}{*}{$\begin{array}{c}\text { Strain } \\
\text { energy } \\
\text { function }\end{array}$} & \multicolumn{2}{|c|}{$\begin{array}{c}\text { Minimum } \\
\text { of all } \\
\text { samples } \\
(0.00128 \mathrm{~m})\end{array}$} & \multicolumn{2}{|c|}{$\begin{array}{c}\text { Average } \\
\text { of all } \\
\text { points } \\
(0.00164 \mathrm{~m})\end{array}$} & \multicolumn{2}{|c|}{$\begin{array}{c}\text { Sample } \\
\text { specific } \\
(0.00167 \mathrm{~m})\end{array}$} & \multicolumn{2}{|c|}{$\begin{array}{c}\text { Average } \\
\text { of three } \\
\text { points } \\
(0.0018 \mathrm{~m})\end{array}$} & \multicolumn{2}{|c|}{$\begin{array}{l}\text { Maximum } \\
\text { of all } \\
\text { points } \\
(0.00218 \mathrm{~m})\end{array}$} \\
\hline & $R_{d}[\mathrm{~m}]$ & $\sigma[\mathrm{kPa}]$ & $R_{d}[\mathrm{~m}]$ & $\sigma[\mathrm{kPa}]$ & $R_{d}[\mathrm{~m}]$ & $\sigma[\mathrm{kPa}]$ & $R_{d}[\mathrm{~m}]$ & $\sigma[\mathrm{kPa}]$ & $R_{d}[\mathrm{~m}]$ & $\sigma[\mathrm{kPa}]$ \\
\hline Yeoh & 0.00436 & 370 & 0.00516 & 414 & 0.00522 & 418 & 0.00545 & 431 & 0.00603 & 466 \\
\hline Marlow & 0.00434 & 369 & 560 & 441 & 0.00573 & 449 & 0.00637 & 490 & / & / \\
\hline
\end{tabular}

Table 2 The effect of sample thickness on the maximum radial displacement $\left(R_{d}\right)$ and maximum von Mises stress $(\sigma)$ predicted by the FE model of thoracic (a) and abdominal (b) aorta, subjected to a physiologic cardiac activity. The listed strain-energy functions assured the best fitting of the experimental data and a stable numerical outcome. Unstable numerical outcome is indicated by "/, meaning that non physical oscillations were observed. 


\begin{tabular}{cccccc}
\hline $\begin{array}{c}\text { Strain-energy } \\
\text { function }\end{array}$ & $\begin{array}{c}\text { Minimum } \\
\text { of all } \\
\text { samples } \\
(\mathbf{0 . 0 0 1 2 8} \mathbf{~ m})\end{array}$ & $\begin{array}{c}\text { Average } \\
\text { of all } \\
\text { points } \\
\mathbf{( 0 . 0 0 1 6 4} \mathbf{~ m})\end{array}$ & $\begin{array}{c}\text { Sample } \\
\text { specific } \\
(\mathbf{0 . 0 0 1 6 7} \mathbf{~ m})\end{array}$ & $\begin{array}{c}\text { Average } \\
\text { of three } \\
\text { points } \\
(\mathbf{0 . 0 0 1 8} \mathbf{~ m})\end{array}$ & $\begin{array}{c}\text { Maximum } \\
\text { of all } \\
\text { points }\end{array}$ \\
\hline Marlow & 27.61 & 21.55 & 21.16 & No aneurysm & 16.21 \\
\hline
\end{tabular}

Table 3 Critical pressure values $[\mathrm{kPa}]$ predicted to form aneurysm in a homogeneous FE geometry of abdominal aorta, which behaviour is evaluated for five different sample thickness values. No aneurysm indicates that no aneurysm is predicted 
(a)

\begin{tabular}{|c|c|c|c|c|c|}
\hline $\begin{array}{l}\text { Localized } \\
\text { thickness } \\
\text { reduction }\end{array}$ & $\begin{array}{c}\text { Minimum } \\
\text { of all } \\
\text { samples } \\
(0.00212 \mathrm{~m}) \\
\end{array}$ & $\begin{array}{c}\text { Sample } \\
\text { specific } \\
(0.0022 \mathrm{~m}) \\
\end{array}$ & $\begin{array}{c}\begin{array}{c}\text { Average } \\
\text { of three } \\
\text { points }\end{array} \\
(0.00247 \mathrm{~m})\end{array}$ & $\begin{array}{c}\text { Average } \\
\text { of all } \\
\text { points } \\
(0.00256 \mathrm{~m}) \\
\end{array}$ & $\begin{array}{c}\text { Maximum } \\
\text { of all } \\
\text { points } \\
(0.00305 \mathrm{~m}) \\
\end{array}$ \\
\hline $\begin{array}{c}\text { Ring } \\
\text { imperfection }-50 \%\end{array}$ & 24.55 & 23.44 & 21.08 & 20.34 & 17.06 \\
\hline $\begin{array}{c}\text { Smooth } \\
\text { imperfection }-50 \%\end{array}$ & 28.53 & 27.22 & 24.48 & 23.61 & 19.82 \\
\hline $\begin{array}{c}\text { Smooth } \\
\text { imperfection }-40 \%\end{array}$ & 33.13 & 31.65 & 28.45 & 27.45 & 23.04 \\
\hline $\begin{array}{c}\text { Smooth } \\
\text { imperfection - } 30 \%\end{array}$ & 39.27 & 37.51 & 33.73 & 32.52 & 27.30 \\
\hline $\begin{array}{c}\text { Smooth } \\
\text { imperfection }-25 \%\end{array}$ & $\begin{array}{c}\text { No } \\
\text { aneurysm }\end{array}$ & $\begin{array}{c}\text { No } \\
\text { aneurysm }\end{array}$ & $\begin{array}{c}\text { No } \\
\text { aneurysm }\end{array}$ & $\begin{array}{c}\text { No } \\
\text { aneurysm }\end{array}$ & $\begin{array}{c}\text { No } \\
\text { aneurysm }\end{array}$ \\
\hline
\end{tabular}

(b)

\begin{tabular}{cccccc}
\hline $\begin{array}{c}\text { Localized } \\
\text { thickness } \\
\text { reduction }\end{array}$ & $\begin{array}{c}\text { Minimum } \\
\text { of all } \\
\text { samples } \\
(\mathbf{0 . 0 0 1 2 8} \mathbf{~ m})\end{array}$ & $\begin{array}{c}\text { Average } \\
\text { of all } \\
\text { points } \\
(\mathbf{0 . 0 0 1 6 4} \mathbf{~ m})\end{array}$ & $\begin{array}{c}\text { Sample } \\
\text { specific } \\
(\mathbf{0 . 0 0 1 6 7} \mathbf{~ m})\end{array}$ & $\begin{array}{c}\text { Average } \\
\text { of three } \\
\text { points } \\
(\mathbf{0 . 0 0 1 8} \mathbf{~ m})\end{array}$ & $\begin{array}{c}\text { Maximum } \\
\text { of all } \\
\text { points } \\
(\mathbf{0 . 0 0 2 1 8} \mathbf{~ m})\end{array}$ \\
\hline $\begin{array}{c}\text { Ring } \\
\text { imperfection -50\% }\end{array}$ & 13.23 & 10.34 & 10.16 & 9.41 & 7.76 \\
\hline
\end{tabular}

Table 4 Critical pressure values $[\mathrm{kPa}]$ predicted to form aneurysm in a not homogeneous model of thoracic (a) and abdominal (b) aorta, evaluated for five different sample thickness values. A geometrical ring imperfection is introduced to reduce the thickness in the middle of the FE model. No aneurysm indicates that no aneurysm is predicted 